\title{
A review on current status of COVID19 cases in Maharashtra state of India using GIS: a case study
}

\author{
B. G. Kodge ${ }^{1}$ (])
}

Received: 12 May 2020/Revised: 18 July 2020/Accepted: 21 July 2020/Published online: 27 July 2020

(C) Korean Spatial Information Society 2020

\begin{abstract}
The coronavirus is showing its strength and spreading exponentially in all the corners of India. Due to this, India is moving under a pandemic situation and most of the states are badly suffering from it. The Maharashtra state in India is a highly infected state and has maximum number of COVID19 (Corona Virus Disease 2019) cases. Therefore, this paper aims to study the current scenario of COVID19 cases in Maharashtra state using the geo-visualization techniques. The paper deals with the district wise current situations showing through compiled maps of COVID19 cases and also presents the detailed ward wise map of COVID19 cases of Mumbai city which has the highest number of cases in Maharashtra state. This review briefly covers the introduction, current cases, recovered cases, deceased cases, predictions, supports and preventive measures taken by authorities, and some basic advices and suggestions; however these are subjected to change in due course of time as is the number of cases and mortality.
\end{abstract}

Keywords COVID19 - GIS - Maharashtra state - Spatial data analysis - Mumbai City · Pandemic · Coronavirus . Emergency

\section{B. G. Kodge}

kodgebg@gmail.com

1 Department of Computer Science and Information Technology, Swami Vivekanand College, Udgir, Latur, Maharashtra 413517, India

\section{Introduction}

The year 2020 is begins with a huge challenge called COVID19 in India too. The first case of COVID19 in India was reported on 30 January 2020, originating from China. After four months this disease spread in almost all parts of the country. The COVID19 is increasing day by day in India and the Maharashtra state has the highest number of COVID19 infected cases in the first week of May 2020. Today the whole world is facing several kinds of issues which are originated due to COVID-19. Day by day the situations are becoming critical to control the COVID-19 cases by the local administrators, state governments and central government as well. The entire world is not only losing their economical strengths but also lost millions of lives till date in several countries including India.

COVID19 is an infectious disease caused by a newly discovered coronavirus. Most of the people infected with the COVID19 virus will experience mild to moderate respiratory illness and recover without requiring special treatment. Old age $(60+$ years $)$ people, and those with underlying medical problems like cardiovascular disease, diabetes, chronic respiratory disease, and cancer are more likely to develop serious illness [1].

Coronaviruses circulate in some wild animals and have the capability to transmit from animals to humans. These viruses can cause respiratory symptoms in humans, along with other symptoms of common cold and fever.

There are no specific treatments for coronaviruses to date. However, one can avoid infection by maintaining basic personal hygiene and social distancing from infected persons [2].

The intellectuals are advised year 2020 is not to use for earning money or to develop the businesses/enterprises. It's a time to survive our self and our family. Now everyone 
has to maintain the social distances and to follow the guidelines which are publishing from the government and other concern institutions time to time.

Adopting the proper maintenances which are according to the said guidelines only can make us safe like "stay in home and stay safe". No other mode of survival methods will save us from Corona virus. But another side, only sitting inside the home will not work to survive our-self and our family members as well.

For some kinds of essential home needs, goods, and provisional items we have to go out and purchase the required materials from shops/market. While purchasing also there are several guidelines which we need to be follow to avoid the Corona virus infection.

The guidelines can be maintained in the areas where the sufficient distance and land are available, but in some cases like Mumbai city it's very difficult to maintain the guidelines properly, due to this factor the Mumbai has the highest Corona affected cases i.e. 13,739 among 22,117 cases of Maharashtra state out of total 67,325 cases in India today (11/05/2020 at 12:02 PM). The numbers of cases are very serious and are increasing day by day $[3,4]$.

\section{Review of literature}

In a study by Arti (2020) noticed that the lock-down and isolation are the important techniques to prevent the spreading of the disease. They studied the effect of these prevention techniques on the spread of Covid19 mathematically, and propose a new mathematical model to predict the new cases or total infected cases in practical scenario. This prediction is very much required to prepare medical set-ups and proceed for future plan-of-action. A new model for constrained scenario is proposed for Covid19 spread. A tree-based model is considered, in which some people are quarantined and few are left undetected (hidden nodes) because of various reasons like symptoms not shown, hiding travel history, etc., and these hidden nodes spread the disease in community [5].

In an another study made by Varsha Kachroo (2020) reviewed the possible mode of transmission, definitions, some basic advices, diagnosis, treatment and management protocol being followed right now in India; however subjected to change in due course of time as is the number of cases and mortality. The health care personnel are doing their job perfectly and so is the Government, but what is important for everyone being a citizen of India is to maintain social distancing and follow advisories strictly from time to time so that we can make way for our own lives and lives of our dear ones [6].

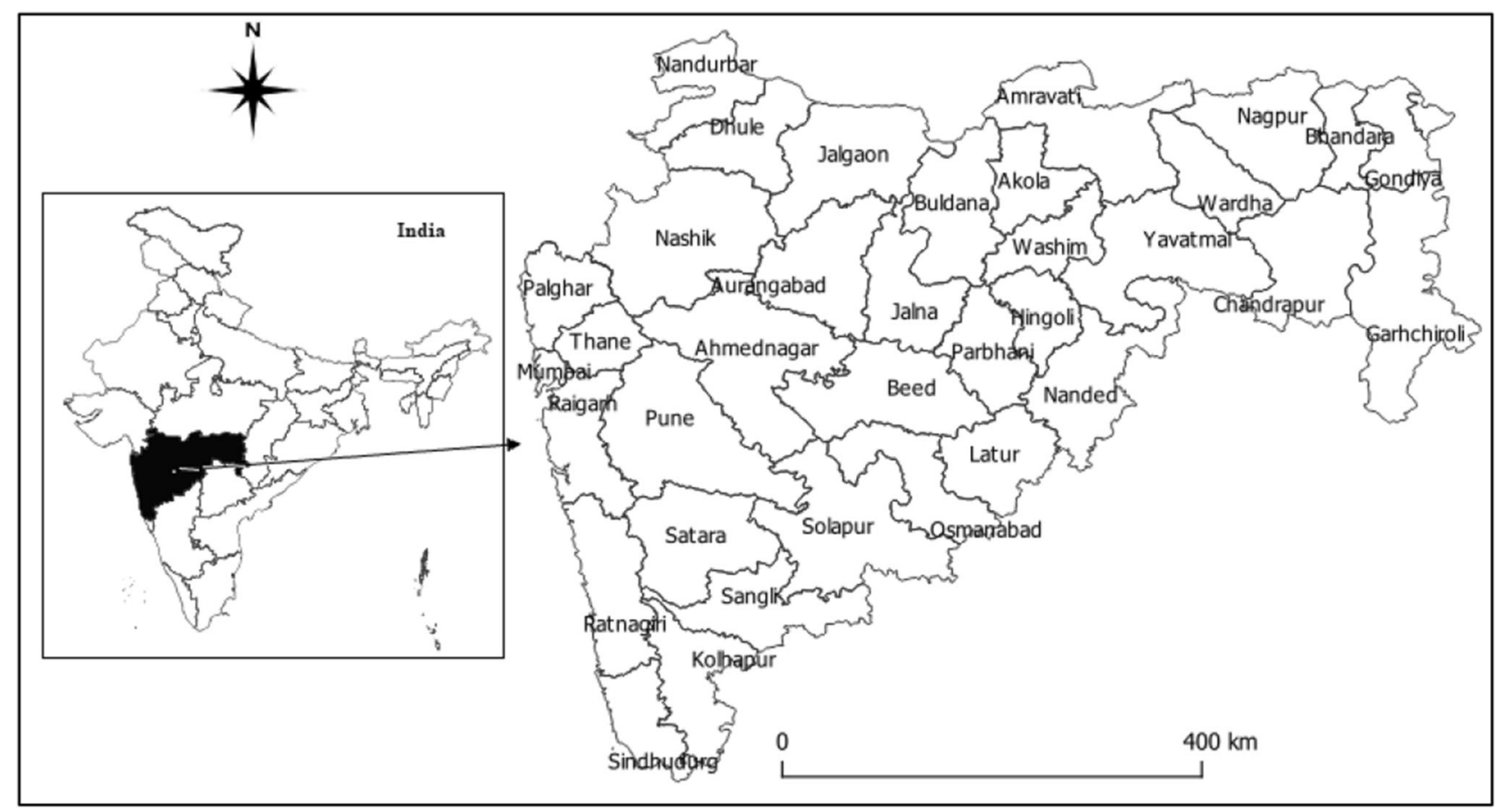

Fig. 1 Study area (Maharashtra state in India) 
Fig. 2 The status map of COVID19 cases in India

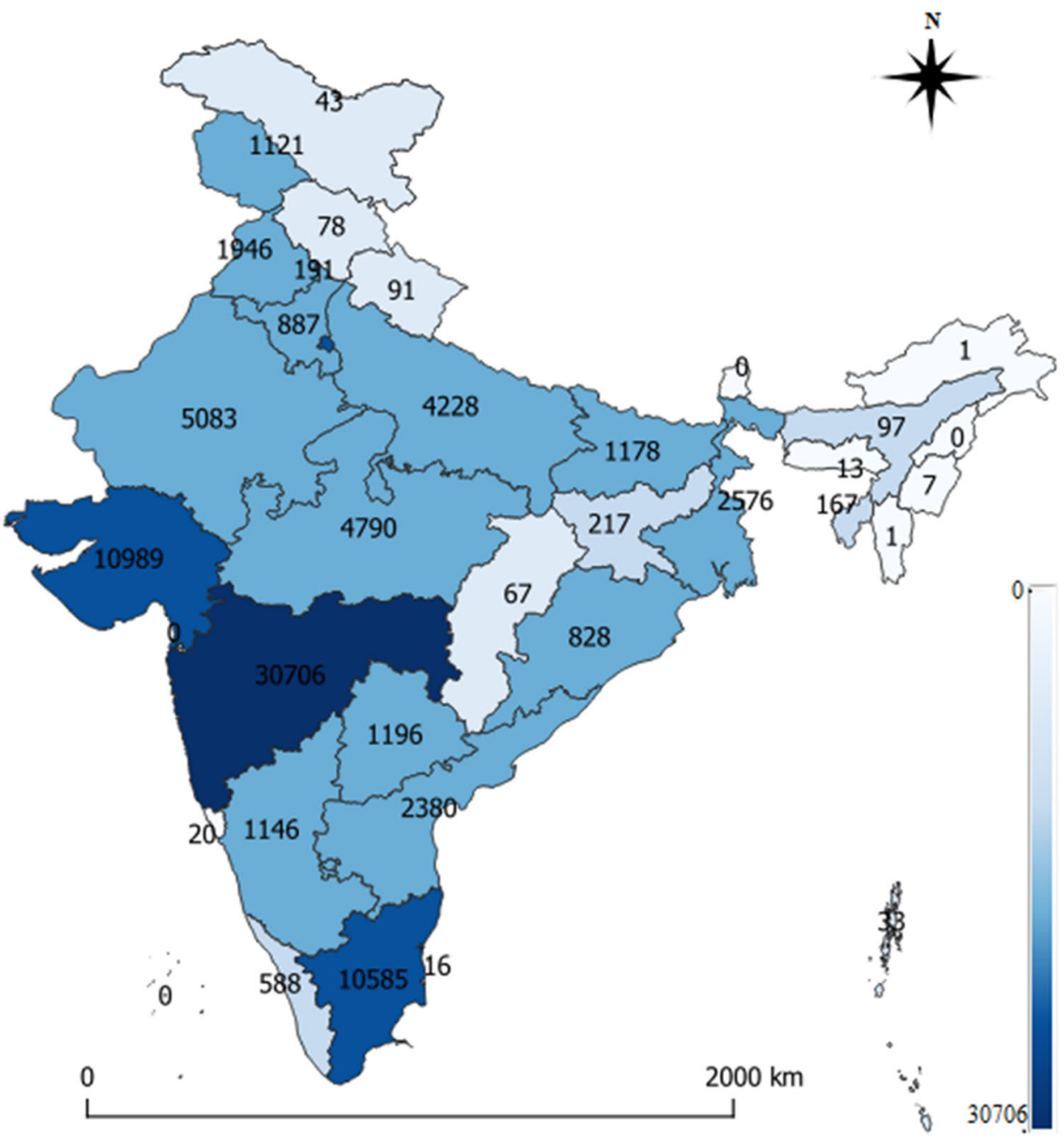

Di Gennaro (2020) performed a narrative review to describe existing literature with regard to Corona Virus Disease 2019 (COVID-19) epidemiology, pathophysiology, diagnosis, management and future perspective. MEDLINE, EMBASE and Scopus databases were searched for relevant articles. Although only when the pandemic ends it will be possible to assess the full health, social and economic impact of this global disaster, this review represents a picture of the current state of the art. In particular, we focus on public health impact, pathophysiology and clinical manifestations, diagnosis, case management, emergency response and preparedness [7].

Gupta et al. (2020) has shown the current situation of coronavirus spread in India along with the impact of various measures taken for it. With the help of data sources (till 7th-8th April 2020) from various state units of India and Ministry of Health and Family Welfare, Government of India, this study presents various trends and patterns. This study answers six different research questions in a comprehensive manner. It has been reported that growth rate of infected cases has been controlled with the help of National Lockdown, however some uncontrolled mass level events had negatively impacted the infected cases [8].

\section{Study area}

The Maharashtra state has 36 districts and is of third largest (area) in India. It is covered by Arabian sea at west side and the Gujarat and Madhya pradesh at north side. The state Goa and Karnataka are located at its south side and the state Telangana and Chhattisgarh are at its east side. The location (study area) of Maharashtra state in India is shown in Fig. 1. The Mumbai is a capital of Maharashtra state and is of India's most populous city with a population of 13 Million. It is located on Salsette Island off the coast of Maharashtra. Originally seven islands, they were merged in the eighteenth century to form one large island.There are three hill ranges with the city limits. The Ghatkopar Hills are present near the station of Ghatkopar. The hill range 
Table 1 District wise COVID19 cases in Maharashtra state of India

\begin{tabular}{|c|c|c|c|c|c|c|}
\hline S. no & Districts & Zone & Cases & Active & Recovered & Deceased \\
\hline 1 & Ahmednagar & Orange & 72 & 34 & 35 & 3 \\
\hline 2 & Akola & Red & 236 & 151 & 71 & 14 \\
\hline 3 & Amravati & Orange & 102 & 33 & 56 & 13 \\
\hline 4 & Aurangabad & Red & 873 & 588 & 260 & 25 \\
\hline 5 & Beed & Orange & 1 & 0 & 1 & 0 \\
\hline 6 & Bhandara & Orange & 1 & 0 & 1 & 0 \\
\hline 7 & Buldana & Orange & 26 & 1 & 24 & 1 \\
\hline 8 & Chandrapur & Orange & 5 & 3 & 2 & 0 \\
\hline 9 & Dhule & Red & 77 & 45 & 24 & 8 \\
\hline 10 & Garhchiroli & Green & 0 & 0 & 0 & 0 \\
\hline 11 & Gondiya & Green & 1 & 0 & 1 & 0 \\
\hline 12 & Hingoli & Orange & 66 & 15 & 51 & 0 \\
\hline 13 & Jalgaon & Red & 250 & 168 & 52 & 30 \\
\hline 14 & Jalna & Orange & 21 & 14 & 7 & 0 \\
\hline 15 & Kolhapur & Orange & 27 & 18 & 8 & 1 \\
\hline 16 & Latur & Orange & 34 & 12 & 21 & 1 \\
\hline 17 & Mumbai & Red & 18,555 & 14,599 & 3260 & 696 \\
\hline 18 & Nagpur & Red & 352 & 191 & 159 & 2 \\
\hline 19 & Nanded & Orange & 59 & 31 & 24 & 4 \\
\hline 20 & Nandurbar & Orange & 22 & 4 & 16 & 2 \\
\hline 21 & Nashik & Red & 835 & 535 & 265 & 35 \\
\hline 22 & Osmanabad & Green & 7 & 4 & 3 & 0 \\
\hline 23 & Palghar & Orange & 390 & 241 & 136 & 13 \\
\hline 24 & Parbhani & Orange & 6 & 4 & 1 & 1 \\
\hline 25 & Pune & Red & 3647 & 2007 & 1452 & 188 \\
\hline 26 & Raigarh & Orange & 414 & 303 & 99 & 12 \\
\hline 27 & Ratnagiri & Orange & 91 & 75 & 13 & 3 \\
\hline 28 & Sangli & Orange & 45 & 14 & 30 & 1 \\
\hline 29 & Satara & Red & 131 & 71 & 58 & 2 \\
\hline 30 & Sindhudurg & Green & 10 & 8 & 2 & 0 \\
\hline 31 & Solapur & Red & 371 & 240 & 109 & 22 \\
\hline 32 & Thane & Red & 2257 & 1877 & 359 & 21 \\
\hline 33 & Wardha & Green & 2 & 1 & 0 & 1 \\
\hline 34 & Washim & Green & 3 & 2 & 1 & 0 \\
\hline 35 & Yavatmal & Orange & 99 & 59 & 50 & 0 \\
\hline
\end{tabular}

runs parallel to the Central Railway track and is inhabited by slums. During the monsoon season, landslides are common. The Trombay Hills occupy a large portion of Trombay on the eastern part of the city. The highest hill is

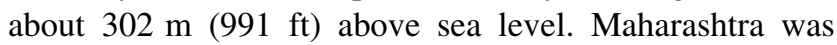
formed on 1 May 1960 by splitting the bilingual Bombay State, which had existed since 1956, into majority Marathi speaking Maharashtra. Maharashtra is the most industrialised state in India while state capital Mumbai is India's financial and commercial capital. The state continues to be the single largest contributor to the national economy with a share of $15 \%$ in the country's gross domestic product (GDP) [9].

\section{Research methodology}

The Maharashtra state is listed as a highly infected state in India with respect to the COVID19 infection, and next the states Gujarat (8195), Tamilnadu (7204), Delhi (6923), Rajasthan (3898), Madhyapradesh (3614), Uttarpradesh (3467), as on 17th May 2020.

For this review study I have chosen the Maharashtra state of India to process and analyze the COVID19 data, because the Maharashtra state of India has the highest number of cases. The major aim of this article is to collect, process, analyze and visualize the result in to its geographical form for the easy understating and for further 
Fig. 3 The status map of COVID19 cases in Maharashtra state of India

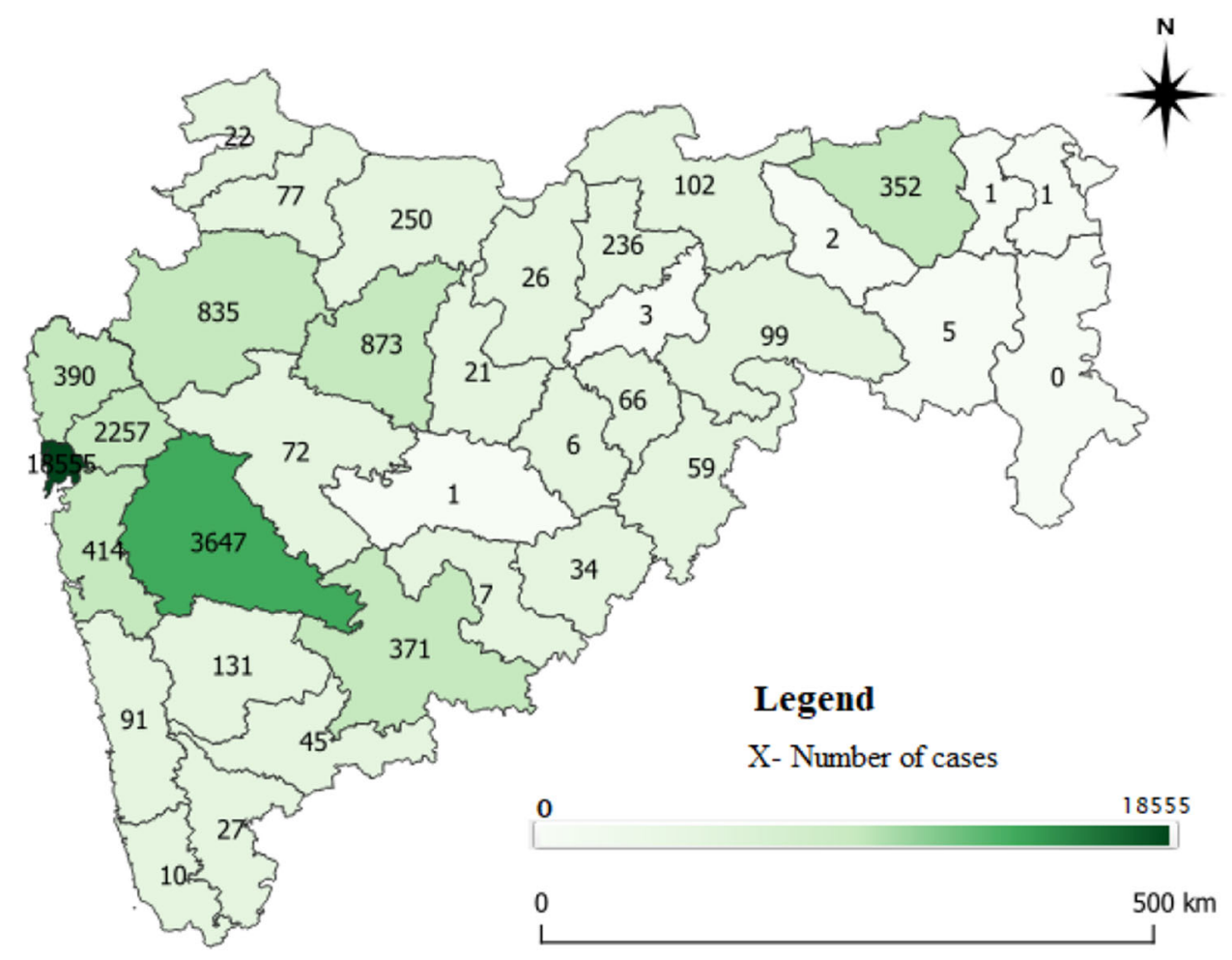

Fig. 4 Pie diagram map of COVID19 cases in Maharashtra state of India

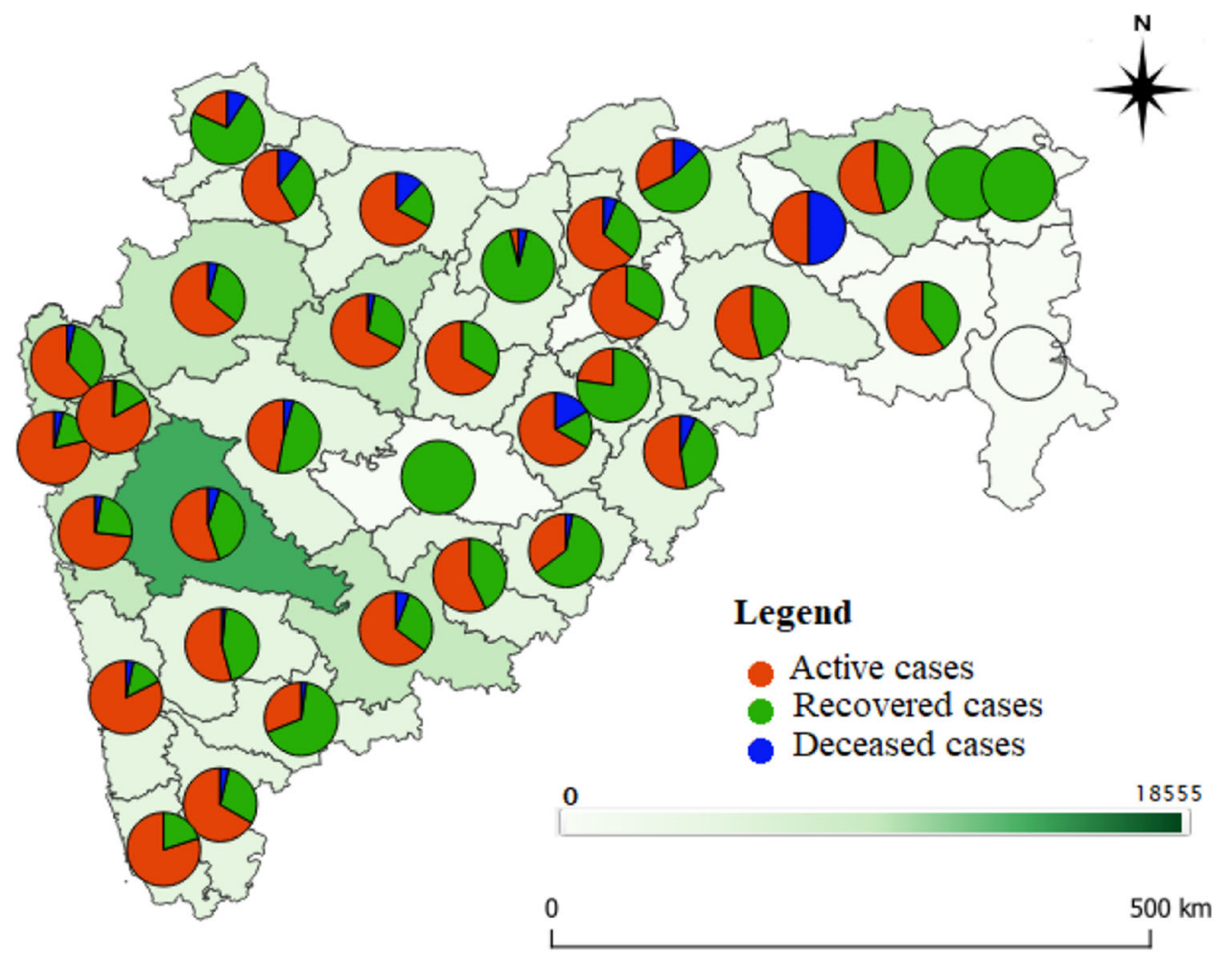

usages. The primary data of COVID19 is collected from Ministry of Health and Family Welfare (https://mohfw.gov. in), COVID19INDIA (https://covid19india.org), and local administrative. The collected data is cleaned and processed into spreadsheets and arranged in the required manner. Next the geographical data such as base layers and other shapefiles are collected from NRSC (National Remote Sensing Centre), IIRS (Indian Institute of Remote Sensing), 
Fig. 5 Maharashtra district wise COVID19 zone map

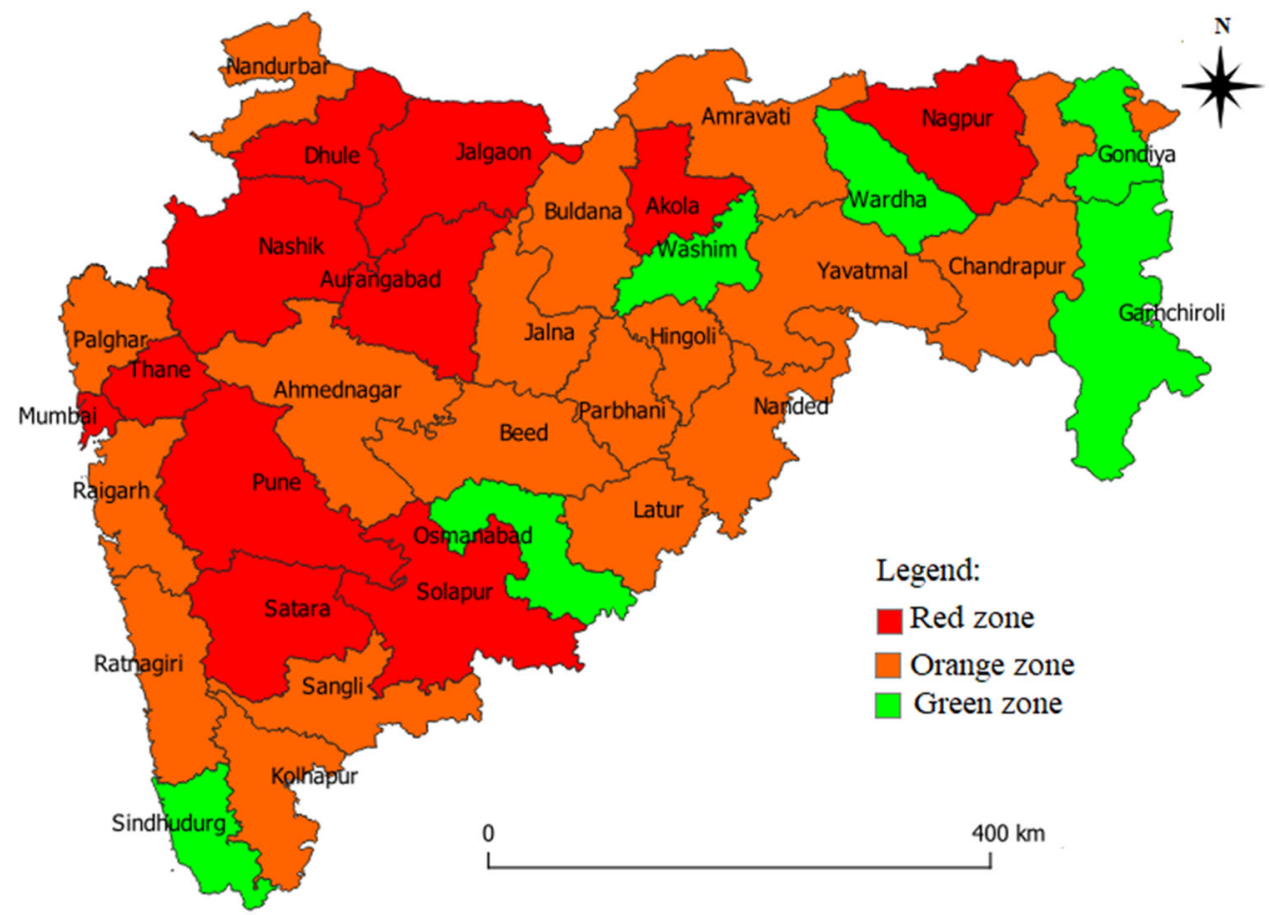

POSTGRESQL, POSTGIS, and QGIS. The combined geospatial and COVID19 data is queried using Python console and processed the required results.

\section{Results and discussions}

After processing and integrating the COVID19 and geospatial data, I have compiled and generated a state wise graduated color map of India which is shown in the Fig. 2. The dark blue colored states in Fig. 2 are the most infected and their numbers of cases are also displayed on it. The state Maharashtra is the first from top of COVID19 infected cases i.e. 22,117, and the other states like Gujarat (8195), Tamil Nadu (7204), Delhi (6923), Rajasthan (3898), Madhya Pradesh (3614), Uttar Pradesh (3467), and so on.

The data available in Table 1 showing the details of district wise COVID19 cases of Maharashtra state of India. With respect to this data (Table 1), I have generated a district wise map to show the current status of COVID19 cases in Maharashtra state of India.

In Fig. 3 the darken green shaded districts like Mumbai, Pune, and Thane are having the highest cases and districts Nashik, Aurangabad, Palghar, Nagpur and Solapur has middle range of number of cases in Maharashtra state.

The map shown in Fig. 4 is generated to show the number of COVID19 active cases, number of recovered cases and the number of deceased cases in each district using pie diagrams. 
The color of the total number of cases of each district displayed in bold style represents the zone of that respective district. The separate district wise COVID19 zone (Red, Orange and Green) map is also generated and shown in Fig. 5. There are 12 districts in red zone, 18 in orange zone and 6 in green zone. As maximum number of districts fall under the red and orange zone, it is a grievous issue.

Mumbai is the second most populous city in India after Delhi and the seventh most populous city in the world with a population of 19.98 million. As per Indian government population census of 2011, Mumbai was the most populous city in India with an estimated city proper population of 12.5 million living under Municipal Corporation of Greater Mumbai. Mumbai is the centre of the Mumbai Metropolitan Region, the sixth most populous metropolitan area in the world with a population of over 23.64 million.

Mumbai's population density is of 20,634 people per square kilometers (sq. km.) provides a happy hunting ground for communicable diseases such as covid-19. In Mumbai more than $60 \%$ of COVID19 cases are from most dense wards [10-13].

The Mumbai's COVID19 cases are increasing day by day and reached 18,555 total cases. The ward wise map of COVID19 cases of Mumbai city is shown in Fig. 6. The local administrative are failing to control exponential increment in number of cases. There are several reasons behind un-controlling this situation. The reasons like insufficient land for maintaining social distancing, dense population, common toilets, shared utilities, slums, majority of unclean area, humid atmosphere, and etc.

Whatever the case may be, in all these situations we are having only the solution to protect over selves is to follow all the guidelines properly as more as possible till the COVID19 vaccine or other mode of treatments will come.

\section{Conclusion}

The COVID19's dance of fury in India is in its peak and if it's not controlled now the situation in the month of June and July 2020 will be worst. The information which is generated geographically and shown in this paper is only the current status. The results (Figs. 2, 3, 4, 5 6) are the evidences showing the current status of COVID19 cases in Maharashtra state of India. According to the outcome of this paper, there are 12 districts in red zone, 18 in orange zone and 6 in green zone. As maximum number of districts fall under the red and orange zone, it is a grievous issue and steps should be taken to control the situation and for speedy recovery. The infected cases are increasing on one side, on another side the numbers of recovered cases are also increasing. But at the same time the deceased cases are also increasing enormously. Through all these, we could understand the current situation and should be prepared for the future challenges. However the results published in this paper are subject to change in due course of time.

Acknowledgements As an author of this paper, I am grateful to our entire local administrative of Latur district for providing the local Geospatial and COVID19 data. I am also thankful to the ministry of health and family welfare (Govt. of India), Govt. of Maharashtra, covid19india.org administrative for providing updated COVID19 data for this review study.

\section{References}

1. https://www.who.int/health-topics/coronavirus

2. Ghosh P., Ghosh R., Chakraborty B. (2020). COVID-19 in India: State wise analysis and prediction, medRxiv preprint. Cold Spring Harbor Laboratory Press.https://www.medrxiv.org/con tent/10.1101/2020.04.24.20077792v1.full.pdf. Accessed 10 May 2020

3. https://www.covid19india.org/

4. https://www.mohfw.gov.in/

5. Arti M. K. (2020). Modeling and Predictions for COVID 19 Spread in India. https://doi.org/10.13140/RG.2.2.11427.81444.

6. Kachroo, V. (2020). Novel coronavirus (COVID-19) in India: Current scenario. International Journal of Research and Review, 7(3): (E-ISSN: 2349-9788; P-ISSN: 2454-2237), 435-447. https://www.ijrrjournal.com/IJRR_Vol.7_Issue.3_March2020/ IJRR0058.html. Accessed 10 May 2020

7. Di Gennaro, F., Pizzol, D., Marotta, C., Antunes, M., Racalbuto, V., Veronese, N., et al. (2020). Coronavirus Diseases (COVID19) current status and future perspectives: A narrative review. International Journal of Environmental Research and Public Health. https://doi.org/10.3390/ijerph17082690.

8. Gupta R., Pal S.K., \& Pandey G. (2020). A comprehensive analysis of COVID-19 outbreak situation in India. https://doi.org/ 10.1101/2020.04.08.20058347

9. https://en.wikipedia.org/wiki/Geography_of_Maharashtra

10. https://en.wikipedia.org/wiki/Mumbai

11. https://en.wikipedia.org/wiki/Geography_of_Mumbai

12. https://censusindia.gov.in/maps/Town_maps/mum_muni_corp_ sec.aspx

13. https://stopcoronavirus.mcgm.gov.in/

Publisher's Note Springer Nature remains neutral with regard to jurisdictional claims in published maps and institutional affiliations. 